\title{
Fine fault structure of a moderate earthquake in the 2007 earthquake sequence of Northern Mie, Japan
}

\author{
Yohei Yukutake ${ }^{1,2}$, Tetsuya Takeda ${ }^{1}$, and Kazushige Obara ${ }^{1}$ \\ ${ }^{1}$ National Research Institute for Earth Science and Disaster Prevention, Tennodai 3-1, Tsukuba, Ibaraki 305-0006, Japan \\ ${ }^{2}$ Hot Spring Research Institute, Kanagawa Prefectural Government, Japan
}

(Received March 28, 2008; Revised July 7, 2008; Accepted July 16, 2008; Online published October 15, 2008)

\begin{abstract}
A moderate crustal earthquake $\left(M_{\mathrm{j}}=5.4\right)$ occurred in the northern part of Mie Prefecture, Central Japan, 2007. In order to clarify the fault structure of the main shock and its relation to the active faults, we estimated the precise hypocenter locations and focal mechanisms. For the relocation of the hypocenters, we used the differential time obtained by both manual picking and waveform cross-correlation analysis. The estimated detailed fault structure suggests that the main shock ruptured the southwestward dipping fault plane. We found that the faults of the moderate earthquake possessed complex fault segments. Around the largest aftershock hypocenter, a subsidiary fault plane parallel to the main shock fault was identified. This result suggests that the fault structure around the deep part of the active fault is complicated. The hypocenters of the foreshock and main shock were located in the offset part of the aftershock alignment, implying that they did not occur on the same fault plane. The Chisato Fault and Yokkaichi Fault were located around the upward extension of the aftershock alignment. The main shock probably occurred in the deep parts of these faults.
\end{abstract}

Key words: Earthquake sequence, Northern Mie, aftershocks, hypoDD, fault structure.

\section{Introduction}

A moderate crustal earthquake occurred in the northern part of Mie Prefecture, Central Japan, on April 15, 2007, with a Japan Meteorological Agency (JMA) magnitude $\left(M_{\mathrm{j}}\right)$ of 5.4. The moment magnitude $\left(M_{\mathrm{w}}\right)$ of the main shock determined by the National Research Institute for Earth Science and Disaster Prevention (NIED) F-net was 5.0. The maximum intensity of $\mathrm{V}$ upper on the JMA scale was observed at Kameyama City, which is located in the vicinity of the main shock epicenter. This earthquake partially destroyed several houses. The foreshock $\left(M_{\mathrm{j}}=3.2\right)$ and largest aftershock $\left(M_{\mathrm{j}}=4.6\right)$ occurred in the vicinity of the hypocenter of the main shock 2 min before and $6 \mathrm{~h}$ after the main shock, respectively.

North-south trending active faults of the thrust fault type dominate around the source region of the main shock for a length of approximately $120 \mathrm{~km}$ from Nobi to the Ise Basin. These active faults are related to the formation of the Suzuka and Nunobiki Mountains (Ikeda et al., 2002). The hypocenter of the main shock is located beneath the surface trace of the Mukumoto and Myojyo-gatake Fault (Fig. 1). The surface traces of the Chisato Fault and Yokkaichi Fault are located approximately $15 \mathrm{~km}$ east of the epicenter of the main shock (Fig. 1). These active faults have westwarddipping fault planes (Research Group for Active Faults of Japan, 1991; Organization of the Headquarters for Earthquake Research Promotion, 2005). The northern part of the Yokkaichi Fault was ruptured by the historical large earth-

Copyright (c) The Society of Geomagnetism and Earth, Planetary and Space Sciences (SGEPSS); The Seismological Society of Japan; The Volcanological Society of Japan; The Geodetic Society of Japan; The Japanese Society for Planetary Sciences; TERRAPUB quake that occurred in 1586 (Ishiyama et al., 2007). The hypocenter of the main shock in the 2007 earthquake sequence of Northern Mie is also located at the base of the seismogenic zone (Fig. 1). It is thought that the main shock occurred in the brittle-ductile transition zone. The focal mechanism of the main shock is of the reverse fault type, with the $P$-axis along the EW direction, which is consistent with the mechanism of background seismic activity (Fig. 1).

The determination of the precise hypocenter distribution and focal mechanisms in the source region is important for understanding the structure of the main shock fault and its relation to the surrounding active faults. We relocated these hypocenters with the double-difference relocation algorithm (hypoDD) (Waldhauser and Ellsworth, 2000), using the differential arrival time obtained by both manual picking and waveform cross-correlation analysis. Subsequently, we determined the focal mechanism from the absolute $P$ - and $S H$-wave amplitudes by adding the $P$-wave polarities.

\section{Data and Method}

\subsection{Hypocenter relocation}

We used 56 permanent online stations operated by the NIED Hi-net (Obara et al., 2005), JMA, Kyoto University, and the Earthquake Research Institute of the University of Tokyo (ERI) within a 120-km distance from the epicenter (Fig. 1). We used 725 earthquakes that occurred in the period between April 15 and 23, 2007. The magnitudes of these earthquakes were $\geq 0.2$. We manually picked $P$ and $S$-wave arrival times, $P$-wave polarities, and maximum amplitudes.

The hypoDD algorithm was applied to the double- 


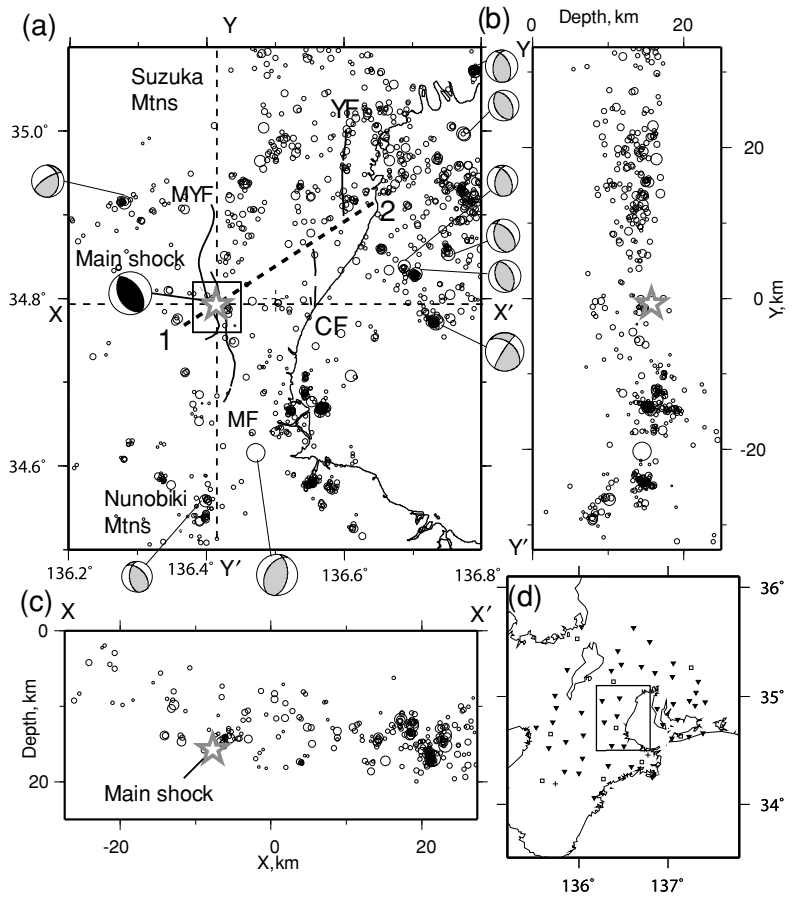

Fig. 1. (a) Map of the northern Mie region, Japan. The star indicates the epicenter of the main shock. The open circles show the ordinary seismic activity determined by NIED Hi-net routine analysis for the period from January 1, 2002 to April 14, 2007. The corresponding focal mechanisms are also shown, and their magnitudes are greater than 3.0. The rectangle corresponds to the aftershock region shown in Fig. 2(a). MYF, MF, YF, and CF indicate the surface traces of the Myojyo-gatake Fault, Mukumoto Fault, Yokkaichi Fault, and Chisato Fault (Research Group for Active Faults of Japan, 1991), respectively. (b) and (c) The depth distribution along the $\mathrm{X}-\mathrm{X}^{\prime}$ and $\mathrm{Y}-\mathrm{Y}^{\prime}$ cross sections, respectively. The width of each section is $\pm 10 \mathrm{~km}$. (d) Map showing the station distribution used in this study (triangles: NIED stations, crosses: ERI and $\mathrm{Ky}$ oto Univ. stations, squares: JMA stations). The rectangle corresponds to that shown in Fig. 1(a).

difference data using the initial hypocenters determined by the Hi-net routine analysis. We used the one-dimensional velocity structure in the Kanto-Tokai region (Ukawa et al., 1984). The differential arrival times for the manually picked $P$ - and $S$-waves were 48,442 and 53,771 pairs, respectively. We also used the differential arrival times obtained by the waveform cross-correlation analysis. The correlation measurements were conducted by using a velocity waveform of a $0.75 \mathrm{~s}$ time window and a $3-20 \mathrm{~Hz}$ band-pass filter, including the manually picked $P$ - or $S$-wave arrival times. We used only the double-difference data with normalized crosscorrelation coefficients $\geq 0.80$. Using this threshold, we obtained cross-correlation data containing 93,295 $P$-wave observations and 105,453 $S$-wave observations. By using both the manually picked and the cross-correlation data, $87 \%$ of all earthquakes were relocated. After the application of the hypoDD algorithm, the root mean square (RMS) of the double-difference time residual decreased from 106 to $91 \mathrm{~ms}$ for the manually picked data and from 98 to $7 \mathrm{~ms}$ for the cross-correlation data.

In order to assess the uncertainty in the hypocenter location, we applied the bootstrap resampling method (Shearer, 1997; Waldhauser and Ellsworth, 2000) for all the relocated events. As a result, the average relative location errors were
$0.021 \mathrm{~km}$ in the EW direction, $0.018 \mathrm{~km}$ in the NS direction, and $0.018 \mathrm{~km}$ in the vertical direction for the events that were relocated using both the manually picked and the cross-correlation data. For the events relocated using only the manually picked data, the average location errors were $0.135 \mathrm{~km}$ in the EW direction, $0.086 \mathrm{~km}$ in the NS direction, and $0.152 \mathrm{~km}$ in the vertical direction.

\subsection{Focal mechanisms}

In order to improve the reliability of the focal mechanism solution, we determined the focal mechanisms from the absolute amplitudes of the $P$ - and $S H$-waves by adding the $P$-wave polarities. After correcting for the instrument response, we determined the spectral levels by fitting the $\omega^{2}$ model (Boatwright, 1978) with an attenuation correction by following the method of Ide et al. (2003). The best-fitting focal mechanism solution for each event was determined by minimizing the residual between the observed and theoretical amplitudes, which was calculated from the far-field solutions for a point-source shear dislocation. A grid search approach was used for determining the strike, dip, and rake angles at $5^{\circ}$ intervals. We determined the focal mechanisms of 19 events for which the number of the $P$-wave polarity was $\geq 10$ by using the relocated hypocenter locations. Subsequently, according to the procedure discussed by Imanishi et al. (2006), we applied the amplitude station corrections that were estimated from the average of the ratios between the observed and theoretical amplitudes. The magnitude of the determined focal mechanisms ranged from 1.4 to 5.7. We estimated the uncertainty in the focal mechanism solution from the standard deviation of the rotation angles (Kagan, 1991) between the best-fitting solution and all the solutions for which the residual was less than 1.1-fold the minimum residual. The average error of all the focal mechanisms was $3.4^{\circ}$

\section{Results}

Figure 2 shows the distribution of the relocated hypocenters. The events relocated by both the manually picked and cross-correlation data are indicated by solid circles, and those relocated by only the manually picked data are indicated by open circles. The corresponding focal mechanisms are also shown in Fig. 2. The aftershocks extend for a length of approximately $3.5 \mathrm{~km}$ along the direction of $\mathrm{N} 30^{\circ} \mathrm{W}$ $\mathrm{S} 30^{\circ} \mathrm{E}$ (Fig. 2(a) and (b)). Most of the focal mechanisms are of the reverse fault type, with the $P$-axis along the NE-SW direction. The trend of the aftershock epicenter distribution is broadly consistent with the strike of the nodal planes of the focal mechanisms. The aftershock depth ranges from 13.5 to $15.0 \mathrm{~km}$ (Fig. 2(b)).

Along the cross section perpendicular to the fault strike of the main shock (Fig. 2(c)), the aftershock distribution is predominantly $\mathrm{SW}$ dipping. The aftershock alignments are consistent with most of the focal mechanisms. Above a depth of $14.5 \mathrm{~km}$ along the A-B and C-D cross sections shown in Fig. 2(c), the aftershock distributions slope downward in the SW direction with a dip of $45^{\circ}$, as illustrated by the red lines. On the other hand, around the main shock hypocenter (C-D cross section in Figs. 2(c) and 3), the SW dipping aftershock alignment is shifted upward in the west side of the main shock hypocenter, as illustrated 


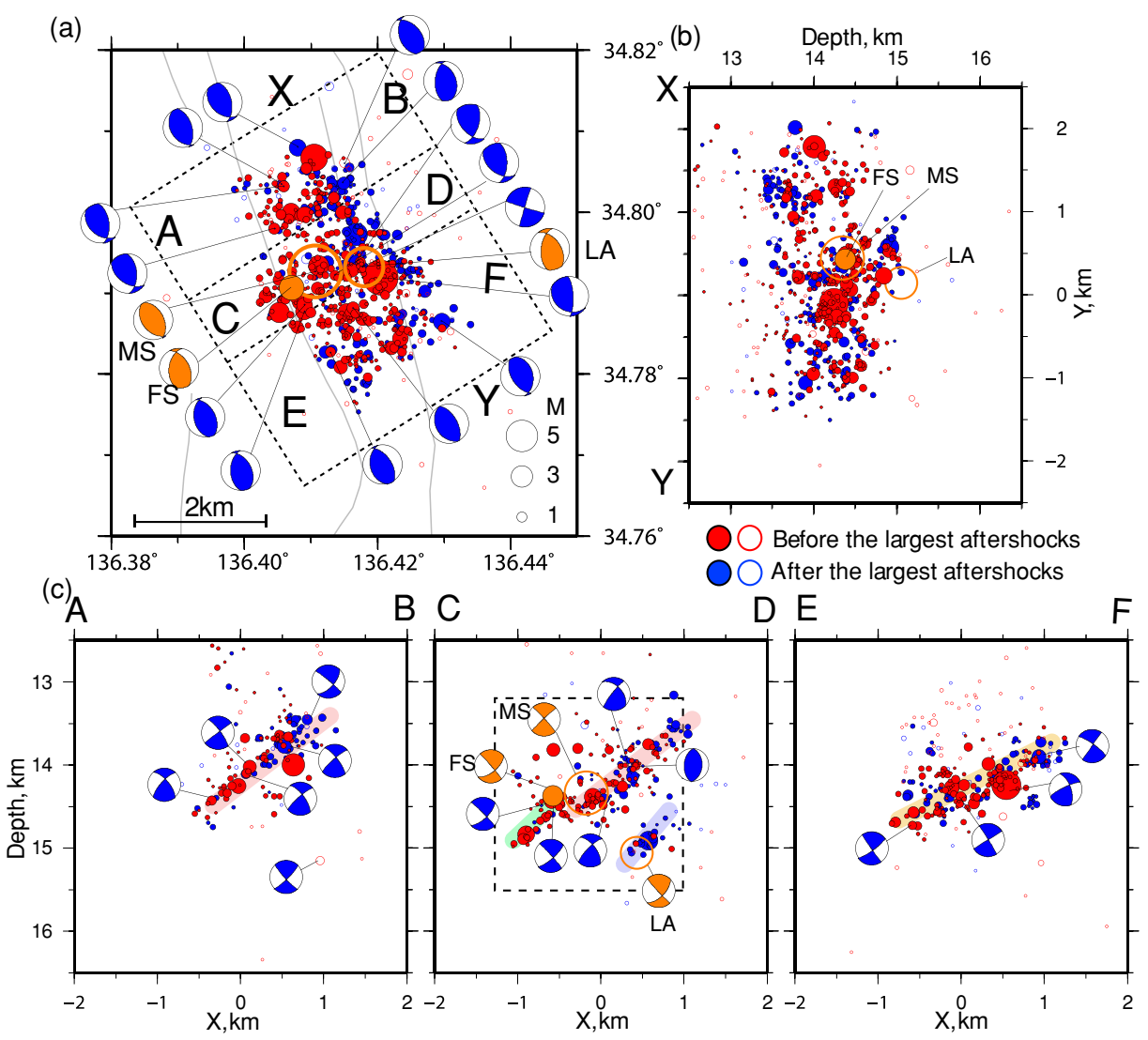

Fig. 2. (a) Map of the relocated earthquake hypocenters determined by the double-difference earthquake algorithm for the period from April 15 to 23 , 2007. (b) Depth section along the $\mathrm{X}-\mathrm{Y}$ cross section. (c) Depth sections along the A-B, C-D, and E-F cross sections. The orange circles show the locations of the foreshock, main shock, and largest aftershock. The red and blue circles indicate the location of the earthquakes that occurred before and after the largest aftershock, respectively. The events relocated by employing both manually picked and cross-correlation data are shown by solid circles, and those relocated by using only the manually picked data are shown by open circles. The corresponding focal mechanisms are also shown. FS, MS, and LA represent the foreshock, main shock, and largest aftershock, respectively.

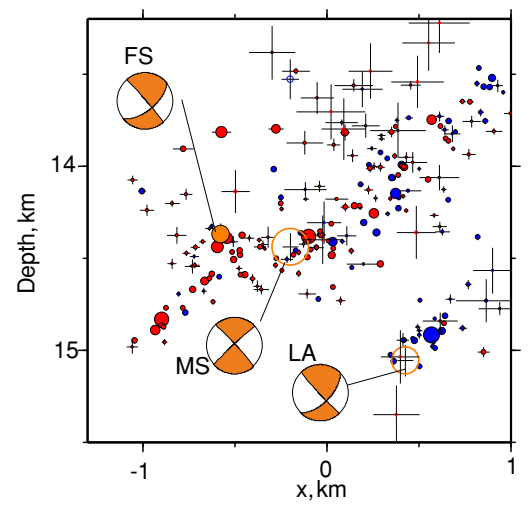

Fig. 3. Magnified plot of the seismicity within the broken box along the C-D cross section in Fig. 2. The error bars indicate the relative location errors in the EW and vertical directions. The significance of each color used for the circles is described in the caption of Fig. 2.

by the green line in Fig. 2(c). Considering the relative location error of the aftershocks, this offset of the aftershock alignment around the main shock hypocenter is significant (Fig. 3). Along the E-F cross section in Fig. 2(c), we can observe the SW-dipping alignment of the aftershocks with a lower dip angle of $30^{\circ}$, as illustrated by the orange line. The spatial difference of the aftershock alignment between

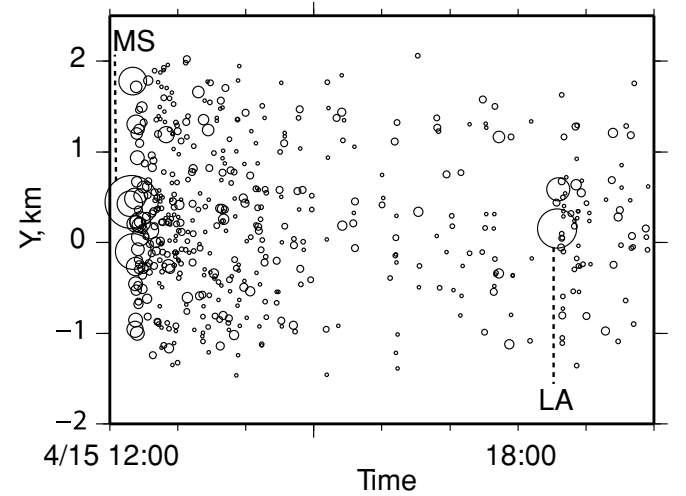

Fig. 4. Time-space diagram projected on the $\mathrm{X}-\mathrm{Y}$ cross section in Fig. 2(b) (along the main shock fault) for the period from 12:00 to 20:00 p.m., April 15, 2007. The $Y$-axis corresponds to that in Fig. 2(b). MS and LA represent the main shock and largest aftershock, respectively.

the $\mathrm{C}-\mathrm{D}$ and $\mathrm{E}-\mathrm{F}$ cross sections is significant within the relative location error. Focal mechanisms corresponding to the SW-dipping nodal plane with a low dip angle $\left(30^{\circ}\right)$ are also observed at $X=0.5 \mathrm{~km}$ and depth $=14.2 \mathrm{~km}$ along the E-F cross section in Fig. 2(c). These results imply that the main shock fault in the southern part of the aftershock region has a lower dip angle. 


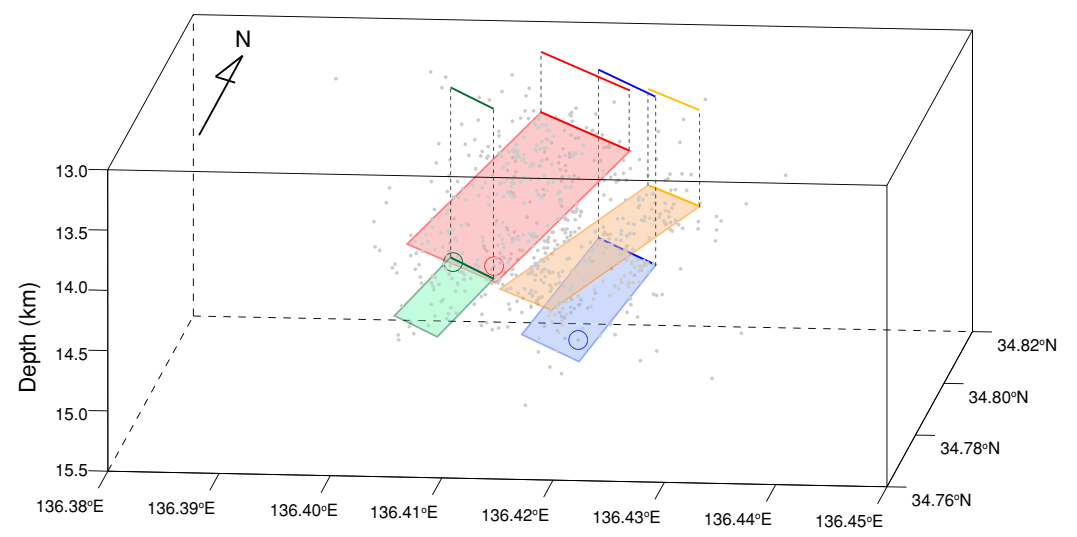

Fig. 5. Perspective view of the fault plane orientations inferred from the relocated aftershock distributions. The green, red, and blue open circles show the location of the foreshock, main shock, and largest aftershock, respectively. The gray dots show the relocated hypocenters.

The largest aftershock is located at the deepest point of the aftershock distribution (Fig. 2(b) and C-D cross section in Fig. 2(c)). The time-space diagram projected on the $\mathrm{X}-$ $Y$ cross section in Fig. 2(b) (along the main shock fault) is shown in Fig. 4. Around the hypocenter of the largest aftershock, most of the aftershocks were activated immediately after the occurrence of the aftershock (Figs. 3 and 4). Thus, the aftershocks in this area are probably associated with the largest aftershock, and they are also distributed in a SW-dipping direction (Figs. 2(c) and 3).

\section{Discussion}

We have modeled the fault structure on the basis of the relocated aftershock distribution and focal mechanisms, as shown in Fig. 5. We can identify four individual faults that are consistent with the aftershock distributions and focal mechanisms. This fault model indicates that the main shock ruptured the SW-dipping faults. Within $1 \mathrm{~h}$ after the occurrence of the main shock, the aftershocks spread to the entire aftershock region (Fig. 4), except around the largest aftershock hypocenter (Fig. 3). Thus, it is likely that the three fault planes (red, orange, and green colored planes in Fig. 5) were nearly coincidentally ruptured during the main shock. The low-dip-angle fault plane in the southern part of the source region suggests that the fault of the main shock has fault segments between the central and southern parts of the source region rather than a simple fault plane. We found that the fault of the moderate earthquake comprises complex fault segments comparable to that of significant large intraplate earthquakes, such as the 2000 Western Tottori earthquake and the 2004 Mid-Niigata Prefecture earthquake (e.g., Fukuyama et al., 2003; Kato et al., 2005; Shibutani et al., 2005).

The offset of the aftershock alignments observed around the main shock hypocenter (Fig. 3) might be associated with the discontinuity of the fault planes, such as a stepover structure. The hypocenters of the foreshock and the main shock are located at opposite ends of the offset in the alignments of the aftershocks. This result suggests that they occurred on adjacent fault planes rather than the same one and that the nucleation of the earthquake occurred at a structurally complex part of the fault. These results support results of previous studies (e.g., Jones et al., 1982; Douglas et

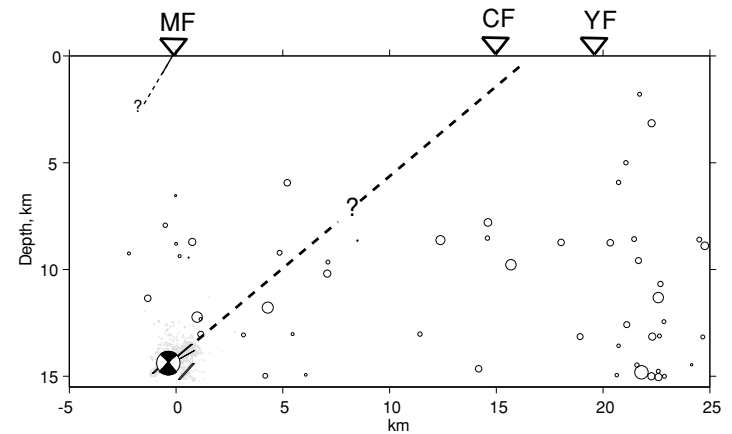

Fig. 6. Schematic diagram along the 1-2 cross section in Fig. 1. The focal mechanism of the main shock is shown at its hypocenter. The fault planes estimated from the relocated hypocenters are also shown. The gray dots indicate the relocated hypocenters. The open circles denote the depth distribution of the ordinary seismicity shown in Fig. 1. The width of the section is $20 \mathrm{~km}$. The triangles show the surface traces of the Mukumoto Fault (MF), Chisato Fault (CH), and Yokkaichi Fault (YF). The thick broken line indicates the extended line from the main shock fault estimated by this study.

al., 1995) in suggesting that the geometric complexity of a fault may be an important factor for earthquake nucleation.

The aftershock distribution around the largest aftershock (Fig. 3) indicates that the subsidiary fault plane parallel to the main shock fault in the brittle-ductile transition zone was reactivated after the main shock. This result suggests that the deep parts of active faults have complicated fault structures rather than a single fracture plane. Several studies have inferred a localized shear zone with a width of more than $1 \mathrm{~km}$ in the deep parts of once-active faults on the basis of observations of exhumed old rocks (e.g., Hanmer, 1988; Norris, 2004). The localized shear zone might contribute to the formation of the complicated fault structure in the deep parts of active faults.

A comparison between our fault model and the surface traces of the surrounding active faults along the 1-2 cross section (Fig. 1) is shown in Fig. 6. The depth distribution of background seismic activities along the $1-2$ cross section is also shown in this figure. Since there is little background seismicity in this region, we cannot find any alignments of the background seismicity that might reveal the relationship between the main shock fault and the surface trace of active 
faults (Fig. 6). The Mukumoto Fault located immediately above the main shock hypocenter slopes westward with a $50^{\circ}-60^{\circ}$ dip angle near the surface; this value is estimated from a reflection survey (Organization of the Headquarters for Earthquake Research Promotion, 2005). Considering the position of the upper limit of the main shock fault, there is no possibility of the main shock being related to the Mukumoto Fault. The surface traces of the Chisato Fault and Yokkaichi Fault are located around the upward extension of the aftershock alignment. These faults also slope westward near the surface (Research Group for Active Faults of Japan, 1991). Sato et al. (2006) found, from the deep seismic reflection profiling of which line is located near the main shock epicenter, that the westward dipping reflector extends to a depth of $11 \mathrm{~km}$ under the surface trace of the Yokkaichi Fault. The main shock hypocenter is located in the vicinity of an extension of the reflector. It is suggested that the main shock occurred in the deep parts of the Chisato Fault or Yokkaichi fault. As shown in Fig. 1(a), however, the strike of the main shock fault is different by approximately $30^{\circ}$ from that of the surface trace of both faults. As discussed above, the fault structure at the depth of the brittle-ductile transition zone would be complicated. Therefore, it is quite likely that such a discrepancy in the fault strike occurs in the case of the rupture at the deep end of the active fault.

Acknowledgments. We are grateful to Dr. F. Waldhauser for the hypoDD program code. Dr. Satoshi Ide provided us with the program for estimating the focal mechanisms. Dr. Kazutoshi Imanishi helped us in calculating the focal mechanisms. We are thankful to Dr. Richard J. Norris and Dr. Fumihito Yamazaki, who greatly helped us to improve this manuscript, and Dr. Kiyoshi Yomogida for editing it. We also thank the Japan Meteorological Agency, Earthquake Research Institute of the University of Tokyo, and Disaster Prevention Research Institute of Kyoto University for allowing us to use their waveform data. A majority of the figures were created using Generic Mapping Tools (GMT) (Wessel and Smith, 1995).

\section{References}

Boatwright, J., Detailed spectral analysis of two small New York State earthquakes, Bull. Seismol. Soc. Am., 68, 1131-1177, 1978.

Douglas, A. D., G. C. Beroza, and W. L. Ellsworth, Foreshock sequence of the 1992 Landers, California, earthquake and its implications for earthquake nucleation, J. Geophys. Res., 100, 9865-9880, 1995.

Fukuyama, E., W. L. Ellsworth, F. Waldhause, and A. Kubo, Detailed fault structure of the 2000 Western Tottori, Japan, Earthquake Sequence, Bull. Seismol. Soc. Am., 93, 1468-1478, 2003.

Hanmer, S., Great Slave Lake shear zone, Canadian Shield: Reconstructed vertical profile of a crustal-scale fault zone, Tectonophysics, 149, 245264, 1988.

Ide, S., G. C. Beroza, S. G. Prejean, and W. L. Ellsworth, Apparent break in earthquake scaling due to path and site effects on deep borehole record- ings, J. Geophys. Res., 108(B5), doi:10.1029/2001JB001617, 2003.

Ikeda, Y., T. Imaizumi, H. Sato, M. Togo, K. Hirakawa, and T. Miyamachi, in Atlas of Quaternary Thrust Fault in Japan, p. 254, University of Tokyo Press, Tokyo, 2002 (in Japanese).

Imanishi, K., Y. Kuwahara, T. Takeda, and Y. Haryu, The seismicity, fault structures, and stress field in the seismic gap adjacent to the 2004 MidNiigata earthquake inferred from seismological observations, Earth Planets Space, 58, 831-841, 2006.

Ishiyama, T., K. Mueller, H. Sato, and M. Togo, Coseismic fault-related fold model, growth structure, and the historic multisegment blind thrust earthquake on the basement-involved Yoro thrust, Central Japan, J. Geophys. Res., 112, B03S07, doi:10.1029/2006JB004377, 2007.

Jones, L. M., B. Wang, S. Xu, and T. J. Fitch, The foreshock sequence of the February 4, 1975, Haicheng Earthquake ( $\mathrm{M}=7.3)$, J. Geophys. Res., 87, 4575-4584, 1982.

Kagan, Y. Y., 3-D rotation of double-couple earthquake sources, Geophys. J. Int., 106, 708-716, 1991.

Kato, A., E. Kurashimo, N. Hirata, S. Sakai, and T. Iwasaki, Imaging the source region of the 2004 Mid-Niigata Prefecture earthquake and the evolution of a seismogenic thrust-related fold, Geophys. Res. Lett., 32, L07307, doi:10.1029/2005GL022355, 2005.

Norris, R. J., Strain localization within ductile shear zone beneath active faults: The Alpine Fault contrasted with the adjacent Otago Fault system, New Zealand, Earth Planets Space, 56, 1095-1101, 2004.

Obara, K., K. Kasahara, S. Hori, and Y. Okada, A densely distributed highsensitivity seismograph network in Japan: Hi-net by National Research Institute for Earth Science and Disaster Prevention, Rev. Sci. Instrum., 76, 021301-doi:10.1063/1.1854197, 2005.

Organization of the Headquarters for Earthquake Research Promotion, Long term Evaluations of Eastern Nunobiki Mountains active fault system, http://www.jishin.go.jp/main/chousa/04apr_nunobiki/index.htm, 2005.

Research Group for Active Faults of Japan, Active Faults in Japan, revised edition, 437 pp., University of Tokyo Press, Tokyo, 1991 (in Japanese).

Sato, H., N. Hirata, K. Koketsu, K. Ito, D. Okaya, T. Iwasaki, T. Ito, K. Kasahara, S. Abe, T. Kawanaka, M. Matsubara, R. Kobayashi, and T. Ikawa, Seismic reflection profiling in the Kanto and Kinki Metropolitan Areas, Japan, Bull. Earthq. Res. Inst. Univ. Tokyo, 81, 233-238, 2006.

Shearer, P., Improving local earthquake locations using the L1 norm and waveform cross correlation: Application to the Whittier Narrows, California, aftershock sequence, J. Geophys. Res., 102, 8269-8283, 1997.

Shibutani, T., Y. Iio, S. Matsumoto, H. Katao, T. Matsushima, S. Ohmi, F. Takeuchi, K. Uehira, K. Nishigami, B. Enescu, I. Hirose, Y. Kano, Y. Kohno, M. Korenaga, Y. Mamada, M. Miyazawa, T. Ueno, H. Wada, and Y. Yukutake, Aftershock distribution of the 2004 Mid Niigata Prefecture Earthquake derived from a combined analysis of temporary online observations and permanent observations, Earth Planets Space, 57, 545-549, 2005.

Ukawa, M., M. Ishida, S. Matsumura, and K. Kasahara, Hypocenter determination of the Kanto-Tokai Observation Network for microearthquakes, Rep. Nat'l. Res. Inst. Earth Sci. Disas. Prev., 53, 1-88, 1984.

Waldhauser, F. and W. L. Ellsworth, A double-difference earthquake location algorithm: Method and application to the Northern Hayward fault, Bull. Seismol. Soc. Am., 90, 1352-1368, 2000.

Wessel, P. and W. H. F. Smith, New version of the generic mapping tools released, Eos Trans. AGU, 76, 329, 1995.

Y. Yukutake (e-mail: yukutake@onken.odawara.kanagawa.jp), T. Takeda, and K. Obara 